\title{
A relação entre as práticas dos docentes na rede pública municipal de ensino e a utilização do material padronizado apostilado
}

Jefferson Antonio do Prado ${ }^{1}$

Resumo: Este artigo aponta a relação entre o trabalho dos docentes em uma rede pública municipal e a utilização do material apostilado utilizado em sala de aula. O estudo partiu de uma revisão bibliográfica e realizou uma pesquisa qualitativa através de um questionário aplicado a professores de língua portuguesa em escolas municipais no interior de São Paulo. Tais docentes trabalham vinculados à secretaria de Educação a qual, por meio de licitação pública, utiliza os didáticos apostilados produzidos por uma empresa que pertence ao mercado editorial educacional. Os resultados investigados apontam que tais apostilas de ensino advindos de um mercado de editoração educacional, ainda que organizem, definam e programem o trabalho pedagógico do professor, estabelecem parâmetros e regras que direcionam o funcionamento e, sobretudo, controlam os comportamentos, procedimentos e resultados de diretores, coordenadores, alunos e, em especial, dos docentes que se apropriam do material.

Palavras-chave: Trabalho Docente; Rede Pública Municipal de Ensino; Material Apostilado

\section{The relationship between teachers' practices in the municipal public education system and the use of apostiled standard material}

Abstract: This article outlines the relation between the work of teachers in municipal public schools in São Paulo state and the use of the handout materials during the classes. Based on a bibliographical review, a qualitative research was carried through questionnaires applied to Portuguese Language teachers. These teachers' jobs are entailed to the Municipal Education Office which purchases handout teaching books developed by a private publishing house; the agreement is made

\footnotetext{
1 Doutor em Ciências da Educação pela Universidad Columbia del Paraguay. Mestre em Educação pela Universidade Estadual Paulista “Júlio de Mesquita Filho" - UNESP. E-mail: pradoj2000@yahoo.com.br
} 
by public bidding. The results of this study reveal that although such materials organize, define and program the pedagogical work of the teacher, they also establish parameters and rules that direct the functioning of the classes and, moreover, control behaviors, procedures and results of directors, coordinators, students, and specially the teachers who use the materials.

Keywords: Teaching Work; Municipal Public Education Network; Handout Material

Por fazer parte da realidade de algumas escolas, dentre elas a rede municipal pública, o ensino apostilado não deve ser excluído das nossas análises e críticas ao sistema educacional brasileiro. De acordo com Batista (2000, p. 53) "as apostilas costumam ser a pedra bruta garimpada por representantes comerciais de editoras que, submetidas a processos editoriais, daria origem a livros produzidos e comercializados por editoras".

Questionar os materiais didáticos é questionar o próprio ensino que neles se cristaliza, uma vez que não podemos dissociar os materiais do uso que dele se faz, pois não se trata de coisas diferentes, mas de "dois lados da mesma moeda" (GERALDI, 1987, p. 5). A fragmentação do conhecimento, contida nas apostilas de ensino, compartimentalizou o saber, e os conteúdos do ensino foram divididos em cadernos, os quais foram subdivididos em matérias, com aulas, seguindo uma numeração durante o ano letivo.

Tal fragmentação do saber, cujas informações encontram-se contidas na apostila, é considerada valiosa pelos autores elaboradores. Entretanto, reforça e legitima o discurso oficial das redes de ensino privado franqueado de que as apostilas compõem o material ideal e mais adequado para ser adotado e utilizado, redefinindo com isso a marca empresarial (slogan) na instituição escolar, cujo espaço social é institucionalizado. Configura-se esse cenário, portanto, como um "campo de forças". Segundo Bourdieu (1989, p. 373-375),

O campo é um universo complexo de relações objetivas de interdependências entre subcampos ao mesmo tempo autônomos e unidos pela solidariedade orgânica, ou seja, um conjunto de agentes suscetíveis de serem submetidos a participações reais e unidos por interação ou ligações reais e diretamente observáveis. É um campo de lutas pelo poder, entre detentores de poderes diferentes; um espaço de jogo, tendo em comum o fato de possuir uma quantidade de capital específico (econômico ou cultural especialmente) suficiente para ocupar posições dominantes cujas estratégias são destinadas a conservar ou a transformar as relações de força.

Para Bourdieu, o poder exercido no sistema de ensino é de origem simbólica, “invisível que só se exerce com a cumplicidade daqueles que não querem saber que a ele se submetem ou mesmo que o exercem" (BOURDIEU, 1989, p. 31). Esse poder é quase mágico, na medida em que permite obter o equivalente ao que é obtido pela força, graças ao efeito específico da mobilização. Todo poder simbó- 
lico é capaz de se impor como legítimo, dissimulado à força que há em seu fundamento e só se exerce se for reconhecido.

Ao contrário da força nua, que age por uma eficácia mecânica, todo poder age também enquanto poder simbólico. A ordem torna-se eficiente, porque aqueles que a executam a reconhecem e creem nela, prestando-Ihe obediência.

O poder simbólico é, para Bourdieu, uma forma transformada, irreconhecível, transfigurada e legitimada das outras formas de poder. As leis de transformação que regem a transmutação de diferentes espécies de capital em capital simbólico e, em particular, o trabalho de dissimulação e transfiguração que assegura uma verdadeira transformação das relações de força, transforma essas forças em poder simbólico, capaz de produzir efeitos reais, sem gasto aparente de energia (BOURDIEU, 1989, p. 408-411).

Em sua obra A economia das trocas simbólica, sobretudo no capítulo em que discorre sobre sistemas de ensino e sistemas de pensamento, Bourdieu (1999) discorre longamente sobre as modificações sofridas por um dado campo do saber quando este é submetido ao processo de escolarização, ou seja, quando ele se torna uma disciplina escolar.

Isso faz supor que, na interação rotineira do dia a dia, a relação entre o material didático e o profissional docente se figura enquanto relação de poder formal e impessoal, próprio das organizações burocráticas, ditado em nome dos órgãos administrativos do sistema. Poder este que serve de escudo e de justificação para o exercício do poder simbólico.

Os atores (professores) se submetem às exigências e as tarefas a serem executadas, regras a serem cumpridas e todo um aparato burocrático, definido em estatutos e regimentos pré-estabelecidos, que norteiam suas ações e interações dentro da instituição.

Nessa cadeia hierárquica é exercido o poder impessoal, apoiado nas normas regimentais, nas leis e nas ordens vindas dos órgãos administrativos do sistema de ensino. A ordem procede de cima e todos os atores envolvidos estão no mesmo barco, sujeitos ao mesmo estatuto e aos mesmos órgãos administrativos (matriz).

No entanto, se a educação precisa ser vista não como uma mera reprodução, mas sim com algo libertador, dinâmico, com a finalidade até mesmo de colaborar em uma eventual mudança na estrutura social vigente, como pensar o ato de educar de maneira livre e dinâmica? Como pensar em educação desvinculada de um processo maior?

Isso faz parecer, por hipótese, que essa educação que reproduz a ideologia da classe dominante está voltada exclusivamente para o incremento da capacidade, entendida como o simples aprimoramento da força de trabalho. Esse tipo de educação - e podemos também falar da escola - se transforma em uma verdadeira fábrica de mão de obra, preocupando-se mais com as demandas mercadológica do que com a construção do conhecimento. 
A relação entre as práticas dos docentes na rede pública municipal de ensino e a utilização do material padronizado apostilado

A educação tornou-se mercadoria mediante a introdução de mecanismos de mercado no financiamento e gerenciamento das práticas educacionais. Um produto a mais entre os muitos a serem consumidos. Em segundo, porque a ela é atribuída à função de formar a força de trabalho com as "competências" necessárias para atender ao mercado (MORAES, 2001, p. 9).

Tal modelo negligencia o docente e se preocupa com o rendimento qualitativo e quantitativo necessário para cobrir a demanda do mercado na reprodução capitalista. Assim, não se trata de desenvolvimento e até mesmo de capacitação para o trabalho, entendido democraticamente, isto é, com o objetivo de entender a aquisição dos saberes intelectuais, materiais e culturais igualitariamente para todos.

Ainda quanto a essas questões, sabe-se que a modernidade na educação primou pela racionalidade, pela produção de saberes, amalgamando a ideia da disciplina pela crença na responsabilidade do professor pela transmissão de conteúdos. Além disso, imbuiu o educador a dominar não apenas os conteúdos a serem transmitidos, mas também a metodologia por meio da qual atribuiria vida a seu trabalho pedagógico.

\section{Metodologia}

Para dar suporte à pesquisa, recorreu-se ao estudo bibliográfico de autores na filosofia e na educação, como Foucault (2004; 2000), a partir de seu conceito de "poder"2 em especial na sociologia. Também utilizou-se Bourdieu para apropriar-se de alguns de seus valiosos conceitos, como "habitus", "campo" e "poder simbólico", por ele utilizado.

Também foram relevantes as contribuições de Norbert Elias (2001), sobretudo através de seus conceitos de "configuração", "redes", "teias", "tramas", "inter-relações", "interdependências" e "habitus social".

Além da investigação bibliográfica sobre o tema, o trabalho resulta de apontamentos sobre informações empíricas realizadas a partir de pesquisa qualitativa. Optou-se por coletar e examinar dados por meio da aplicação de questionário a professores de língua portuguesa da Educação Básica, do ensino fundamental II, que atuam do $6^{\circ}$ ao $9^{\circ}$ ano em uma cidade no interior do estado de São Paulo..$^{5}$

\footnotetext{
2 Para Foucault (2004) o poder é uma prática social constituída historicamente. São formas díspares, heterogêneas, em constante transformação. Constata Foucault que o poder está por toda parte e provoca ações e uma relação flutuante, não está em uma instituição nem em ninguém.

3 De acordo com Bourdieu (1977), para que um campo funcione (p. 89), "é preciso que haja objetos de disputas e pessoas prontas para disputar o jogo, dotadas de "habitus" (p. 94) que impliquem no conhecimento e reconhecimento das leis imanentes do jogo, dos objetos de disputas, etc. O "habitus", sistema de disposições adquiridas pela aprendizagem implícita ou explícita, que funciona como um sistema de esquemas geradores é gerador de estratégias que podem ser objetivamente afins aos interesses objetivos de seus autores sem terem sido expressamente concebidos para esse fim".

4 Norbert Elias se refere ao habitus social como uma "segunda natureza". Assim, o habitus muda com o tempo, porque a experiência de uma nação, ou de seus membros, está em processo contínuo de mutação, esta, por sua vez, relacionada com os grupos sociais. Os grupos em posição superior, a fim de se distinguir dos outros grupos, criam padrões de comportamento, padrões que, com o passar do tempo, também são adotados pelos outros grupos. "com o passar do tempo, os novos padrões de comportamento deixam de ser conscientes para tornaremse uma segunda natureza - é a essa segunda natureza que se refere quando fala em mudanças na estrutura da personalidade" (LANDINI, 2007, p. 5-6). A identidade dos professores participantes foi mantida em sigilo, tal como consta no Termo de Consentimento Livre e Esclarecido que se encontra em anexo em minha Tese de Doutorado que gerou este Artigo.

${ }^{5}$ A identidade dos professores participantes foi mantida em sigilo, tal como consta no Termo de Consentimento Livre e Esclarecido que se encontra em anexo em minha Tese de Doutorado que gerou este Artigo.
} 
Na condução das respostas obtidas a intenção será observar e perceber se este profissional docente compreende de que forma os valores e as condições de sua atividade interferem ou não em suas práticas educativas.

\section{Análise e reșultados das respostas do questionário}

Após coletadas as respostas dos docentes, as doze perguntas do questionário foram categorizadas em: material apostilado; conteúdo didático apostilado; qualidade da atividade docente; privação da qualidade relacional; temor/receio; tempo; castigo; fiscalização/monitoramento; resistência/reação; condicionamento docente; entendimento da atividade pedagógica.

A fim de deixar os professores à vontade para responder ao questionário, foi-lhes comunicado que a identidade de cada um seria preservada, no intuito de garantir que se sentissem confortáveis e seguros para formular as respostas e suas possíveis críticas. Dessa maneira, optou-se por categorizar os sujeitos das respostas como : Docente A; Docente B; Docente C; Docente D; Docente E; Docente F; Docente G; Docente H.

Diante disso, e a fim de criteriosamente direcionar e discutir as questões propostas, procedo às análises das respostas extraídas do questionário aplicado a cada um dos oito docentes participantes, compreendendo como é a atividade docente de cada um, norteada pelo material didático apostilado que utilizam nas quatro escolas públicas em uma cidade no inteiro do estado de São Paulo.

\section{0 material apostilado e a qualidade da prática docente}

Nesta seção, as perguntas referiram-se a questões a respeito do conteúdo didático apostilado e as implicações deste para a qualidade da atividade docente e para uma possível privação da qualidade relacional. Assim que os oito professores foram questionados, em relação à forma como eles se sentiam quando utilizavam o material apostilado adotado pelo município e, consequentemente, na escola onde lecionam (pergunta 4), sete destes docentes afirmaram sentir um desconforto devido ao cronograma pré-determinado, editado pelo material didático, já que segundo eles tal "pré-determinação" limita os espaços de criação. Apesar disso, de forma geral, os materiais apostilados lhes proporcionavam um suporte, como se observa nas seguintes colocações: 
Sinto-me como se estivesse "encarcerado", isto é, "preso", uma vez que as programações dos conteúdos, na apostila, são extensas e rigidamente cobradas. Porém, de uma maneira geral, confesso que o material me dá um certo suporte e, além disso, posso contar com o planejamento das aulas que são oferecidas (Docente A).

Em relação ao material apostilado, percebo que, quase sempre, "aprisiona" a prática do professor e o deixa limitado em sua criatividade, como se ele estivesse "preso", "amarrado" ao conteúdo. Porém, acredito que este material se trata de um bom mapa de estudos, dirigindo minhas aulas. Mas isso, é óbvio, se o professor souber utilizá-lo (Docente B).

Com relação ao trabalho com material, às vezes, sinto-me "restringido". Tenho essa sensação, em especial, em relação ao tempo que temos para executar com os alunos cada uma das aulas proposta. Além disso, me agonia a colossal quantidade de conteúdos que vêm pré-estabelecidos e que devem ser ensinados aos alunos. Apesar disso tudo, tento compreender, embora angustiado, o material como uma ferramenta facilitadora de minhas aulas, já que os conteúdos vêm pré-determinados e não preciso elaborá-los (Docente C).

O trabalho com apostila possui o "lado positivo e negativo". Eu me sinto na grande parte das vezes como se estivesse "trancafiado", sendo obrigado a dar conta de um cronograma já estabelecido e cobrado Isso, infelizmente, na maioria das vezes, não me permite levar, aos alunos, outros materiais que possam complementar as aulas. 0 saldo positivo disso tudo é que o material já vem elaborado e não me toma tempo para ter de preparar aula. Mas, ainda assim, dia desses, me peguei perguntando: será que sou mesmo professor ou um técnico reprodutor de ideias? (Docente D).

A sensação que tenho é de estar "meio encurralada", pois ainda que eu tenha de cumprir à risca todo material da apostila, acho que ela me dá um direcionamento sobre dos conteúdos que terei de ministrar no dia a dia, aula a aula. Mas, não elimino o fato, nem mesmo a necessidade, de "ter e poder" exercitar outras possibilidades de conteúdos àquela aula dada. Isso seria, para mim, como um "exercício de fuga ao sistema", isto é, à franquia que elabora estes materiais apostilados. Nesse caso, teria liberdade e autonomia de abordar outros e diferentes conteúdos que pudessem somar à aprendizagem de meu aluno, mesmo sabendo que o material já vem com conteúdos pré-elaborados (Docente E).

Quase sempre, ao chegar à aula, me sinto "sufocado", uma vez que gostaria de não só ter, mas também exercitar minha autonomia enquanto professor. E, além disso, poder e conseguir trazer à sala outros materiais ou mesmo ministrar aulas de forma diferenciada, não sendo nem "cobrado" e nem "policiado" pelo sistema no qual estou integrado (Docente F).

Minha sensação é de "limitação", simplesmente pelo fato de ser obrigado a atender a uma ordem superior institucional, para só depois, quem sabe, tentar utilizar na sala de aula, com meus alunos, um conteúdo particular, diferenciado àquele imposto pelo material apostilado que tenho de usar. $O$ único ponto positivo que considero é o fato do material ter aulas preparadas, possibilitando que eu tenha mais tempo livre (Docente $\mathrm{H}$ ).

Essas respostas apontam que os docentes na matéria escolar de língua portuguesa consideram que o material seja um facilitador de suas atividades docentes em sala de aula. Isso evidencia que a oferta dos didáticos-apostilados, cujos conteúdos já vêm definidos por uma empresa educacional que os elabora (rede de franquia), repassados aos professores pela rede municipal, evita que os docentes consumam o pouco tempo que têm organizando e preparando os conteúdos para ministrar em suas futuras aulas.

Tal característica aparece, contudo, mascarada de um valor simbólico, haja vista a necessidade que cada professor tem de trabalhar exaustivamente e dar a maior quantidade de aulas possíveis. Isso corrobora e vai ao encontro das respostas à pergunta sobre a quantidade de aulas que ministravam semanalmente (pergunta 3). 
A relação entre as práticas dos docentes na rede pública municipal de ensino e a utilização do material padronizado apostilado

Nota-se inquestionavelmente nas respostas o quanto o material é impotente por não possibilitar oportunidades de criação e intervenção. Além disso, há a dificuldade nas condições do trabalho docente, visto que as quantidades de aulas semanais são absurdamente exageradas, chegando a alcançar 56 aulas semanais, isto é, uma jornada de $60 \mathrm{~h}$ semanais, divididas entre os períodos matutino, vespertino e noturno. Isso foi observado, também, nas respostas acerca dos defeitos e qualidades mais relevantes do material apostilado (pergunta 5).

Entretanto, existem algumas ideias que são de senso comum em relação aos cadernos apostilados: a questão do tempo, o exorbitante conteúdo da programação, a grande e exaustiva quantidade de informações das atividades e, sobretudo, a perda da qualidade relacional.

Tal apontamento é considerado como um cenário grave, uma vez que veta, fiscaliza, monitora e captura do professor a autonomia e tenciona sua atividade docente. Todas estas questões ficam evidentemente claras nas respostas a seguir:

Tenho 56 aulas semanais, aulas estas que dou em escolas particulares e escolas públicas. Pontos positivos do material: aulas muito detalhadas e tarefas pontuais referentes a cada uma dessas aulas. Pontos negativos: textos longos demais e pouco interessante para o aluno, além, é claro, do excesso de aula e da programação que além exigente é muito cobrada de mim. Isso me faz sentir tencionado, preso, isto é, pressionado (Docente A).

Dou 20 aulas em escola particular e 36 aulas na escola pública municipal. Pontos positivos: o material apostilado facilita e unifica o trabalho docente, além do que possui preços melhores que os livros didáticos. Pontos negativos: A desproporcional quantidade de conteúdo, bem como o tempo escasso para elaborar informações extras à apostilada. Além disso, noto os alunos passivos diante do material apostilado. É como se o conteúdo já proposto não instigasse neles a curiosidade à pesquisa, à reflexão (Docente B).

Atualmente tenho 42 aulas por semana, divididas entre as escolas particulares e pública municipal. Pontos positivos do material: eu aposto na praticidade, pois o conteúdo está programado, ou seja, como já vem pré-ebaborado não exige ainda mais tempo de mim para preparar as aulas. Pontos negativos: Sem dúvida a exigência do tempo, já que tal rigorosidade não me permite administrar outras propostas além daquelas que o material apostilado oferece (Docente $C$ ).

Hoje, ministro 36 aulas por semana, trabalhando na rede particular de ensino e a pública municipal. Pontos positivos do material: conteúdos que são selecionados e divididos aula a aula, o que facilita, sobretudo, meu tempo. Pontos negativos: há um exagero no "excesso" das informações, que estão condicionados a um cronograma escolar, cujos conteúdos, além de extenso, são exigentemente cobrados de mim (Docente D).

Tenho 38 aulas semanais. Acredito que o material atende, digamos que, quase totalmente, as necessidades dos alunos com os textos e atividades que lá estão contidos. Essa seja, talvez, a questão "positiva" dos apostilados. Porém, a demasiada quantidade de atividades oferecidas pelo material, me obriga a executar os conteúdos de maneira "superficial" não possibilitando que eu tenha tempo necessário para trazer aos alunos, e oferecer a eles, outros e novos conteúdos contextualizantes, de determinadas aulas, que considero imprescindíveis ao aprendizado (Docente E).

Hoje conto com 40 aulas semanais, ministradas na rede privada e pública. Pontos positivos: os diversos de textos que o material traz, sobretudo e relação aos gêneros textuais, que utilizo com os alunos, nas aulas de produção textual. Pontos negativos do material apostilado: Os exercícios propostos, são, na maioria das vezes, gramaticalmente descontextualizados e, devido a isso, os alunos apresentam extrema dificuldade em elaborá-lo (Docente F). 
Atualmente tenho 39 aulas semanais, aulas estas que dou em escola da rede pública de ensino, isto é, municipal, e rede particular. Para mim, a principal virtude do material é uniformização do conteúdo. Isso me parece oportuno, pois não causa prejuízo ao aluno que pede transferência para outra escola do município, ou de outro, que trabalhe com o mesmo material apostilado. Além disso, ter em mãos um material com aulas pré-elaboradas não exige que eu elabore um planejamento anual, que poderia, caso eu mesmo elaborasse, conter incoerências. Os pontos negativos que considero mais relevantes que considero são: a contínua e exaustiva preocupação dos professores no que diz respeito ao cumprimento da programação da apostila, bem como o limitante e escasso tempo que não nos permite complementar as aulas com material de apoio (Docente G).

Semanalmente tenho 60 aulas, entre colégio público municipal e particular, entre manhã, tarde e noite. Ponto positivo: a sequência lógica das aulas, bem como a organização destas aulas para os alunos, que ao receberem as apostilas, sabem, previamente, quais exercícios e conteúdos são estudados aula a aula. Quanto aos pontos negativos, sinto falta de trazer aos meus alunos materiais que complementariam a aula ministrada naquela semana. E ainda, o pouco e tencionador "tempo" para ministrar o vasto conteúdo que deve ser dado, aula a aula (Docente H).

\section{As relações coma direção escolar e o cumprimento do cronograma letivo}

Ainda que o material apostilado seja considerado "uma ferramenta que facilite trabalho do docente", já que traz as informações que o professor utilizará com os alunos já elaboradas, e também seja considerado como o " elemento ideal de produtividade", o que realmente se deseja é o cumprimento de um cronograma, pré-estabelecido no início do ano letivo.

Nesse contexto nos deparamos com termos como receio e temor diante dos possíveis atrasos e "castigos", ou seja, das advertências, os quais acontecem mediante atitudes de fiscalização e monitoramento por parte da coordenação e direção escolar. Diante destes fatores, os professores também desenvolvem atitudes de reação e resistência. Ainda assim, a programação se cumpre "em termos", isto é, dentro do prazo estabelecido. Isso se observa no fato de que, em um primeiro momento, todos os docentes afirmaram "sim" à pergunta sobre atender ao que o calendário escolar propõe, mas com ressalvas. Assim se posicionaram os Docentes " $R$ " $e^{\text {" }} C$ ":

Sim, executo a programação no prazo certo, ou seja, no tempo que a coordenação exige de mim. Mas, considero uma "proeza" cumprir em tempo hábil a programação, embora, confesso, desenvolvi tal destreza, porque trabalho há muito tempo com os cadernos didáticos apostilados e, portanto, tenho uma certa experiência com o manejo desses materiais (Docente $\mathrm{R}$ ).

Sim, eu cumpro a programação no tempo adequado e exigido. Como já trabalho há anos com material apostilado, não só na rede púbica de ensino, como também na municipal, adquiri muita experiência e me mantenho em dia com o cronograma. Sei que, dessa forma, vou evitar constrangimentos e problemas futuros com a coordenação da escola (Docente C).

Tais respostas, contudo, são envolvidas pela consciência que esses docentes têm por trabalhar há muito tempo com o perfil do material didático apostilado, isto é, a grande experiência em lidar não só com o material, mas também com seus conteúdos na rede pública de ensino - "Digladiar-se" e "po- 
A relação entre as práticas dos docentes na rede pública municipal de ensino e a utilização do material padronizado apostilado

liciar-se" tal como aponta o Docente "E". Nesse caso, é curioso notar que o professor se utiliza de uma figura de linguagem, no caso uma metáfora, para referir-se ao campo semântico de "guerra".

A programação dos conteúdos é, sem dúvidas, rigorosamente exigente. A abordagem dos conteúdos apostilados, por ser demasiadamente conteudística me "sufoca", pois tenho que me "digladiar" sempre contra o tempo. Sou constantemente policiado pelas exigências do conteúdo, que são elaborados e propostos de maneira não tão eficaz ao aluno (Docente E).

Apesar dessas situações limitantes impostas pela programação pré-estabelecida nos materiais didáticos apostilados, é imprescindível notar, nas respostas, que os docentes exercitam "estratégias de fuga", isto é, criam, invejam, e reinventam "maneiras" de adicionar às aulas outras informações relevantes, educativas, criativas e didáticas que vão além das apostilas.

Além disso, enxergam novas possibilidades de trabalharem com outros conteúdos, apesar de serem conscientes de que suas funções, ou seja, suas atividades em sala de aula como professor são monitoradas, fiscalizadas e, por que não dizer, "domesticadas", isto é, "condicionadas" pelo sistema apostilado de ensino, tal como apontam as seguintes respostas:

Sem dúvida, é quase inexistente a oportunidade de levarmos à sala de aula, aos alunos, outros conteúdos que não sejam aqueles contemplados pela apostila. Entretanto, quando consigo trazer e adicionar algo diferenciado, faço consciente de que o material extra esteja contextualizado ao conteúdo da apostila. No que diz respeito ao programa estabelecido pela escola e pelos cadernos apostilados eu executo. E quanto à programação pré-determinada dos cadernos apostilados, sim, considero de extrema exigência e rigidez, sobretudo porque não me possibilita ir além, ou seja, diversificar (Docente A).

Sim, a possibilidade de incorporação existe, tais como textos, filmes e músicas que, na medida do possível, eu utilizo. Tais aparatos promovem a leitura crítica em complementação à apostila. Porém, ressalto que o uso extra deste material é muito restrito e que antes de utilizá-los, preciso ter o consentimento prévio não só da coordenadora, mas também da diretora. Quanto à programação a considero exigente sim, em especial em detrimento tempo estabelecido. Sim, há exigências produzidas pelo material que me tenciona a prática pedagógica. Uma delas trata-se do fato deste material apostilado não permitir que o educando construa o seu conhecimento, uma vez que oferece fórmulas prontas. Além do que, observo o aluno passivo diante à apostila (Docente B).

Nas aulas, a possibilidade de trabalhar um material extra é rara, em relação ao pouco tempo e a quantidade de informações. Quando posso inferir, o faço trazendo textos informativos e letras de músicas, mas sempre com verificação e autorização prévia da coordenação. Sim, eu considero exigente a programação, pois trazem de uma maneira muito extensa os exercícios aos alunos. Além da abrangência das atividades, observo que as aulas pré-estabelecidas possuem um conteúdo engessado, cujas informações, apenas exploram a memorização e a reprodução dos conceitos mencionados (Docente C).

Até hoje sempre consegui cumprir a meta da escola e atendo ao cumprimento todas as aulas e conteúdos que o caderno apostilado propõem. Acho exigente a programação, pois como já disse não abre tantos espaços para o docente desenvolver "aulas práticas", já que o tempo que temos para cumprir com os cadernos apostilados é muito curto. Assim, considero que aquilo que mais tenciona minha prática pedagógica é a limitação do tempo (Docente D). 
Procuro cumprir, embora às vezes me sinta pressionada, pois ao analisar o número de aulas com a quantidade dos conteúdos, os espaços de interatividade se tornam mais "justos" ou seja "apertados" (Docente E).

A meu ver quando se trabalha "apostilado" fica muito difícil em relação ao conteúdo, utilizar material extra-apostila, principalmente quando o aluno sabe que a instituição leva em consideração na avaliação apenas o que a apostila já traz. É o mesmo o que acontece em concursos públicos em que o candidato só estudará "aquela apostila", em especial se a aprovação estiver atrelada apenas a ela. Sim, eu cumpro a programação exigida em razão das avaliações que serão propostas aos alunos a partir delas. Considero exigente a programação apostilada, uma vez que toda ela está vinculada à avaliação, no caso da escola, ao Saresp e Prova Brasil. Enfim, pior que seja o material, o professor especialista, redobra o seu conhecimento dos assuntos para que a todo o momento possa ensinar ao aluno aquilo que o material não contempla (Docente $\mathrm{H}$ ).

Todas essas respostas mostram que, embora haja uma situação disciplinadora e restritiva para cada um dos docentes, a maioria afirmou que é possível trazer às suas aulas outros conteúdos de materiais didáticos que vão além daqueles pré-estabelecidos e sugeridos pelos cadernos apostilados.

Fica evidente, porém, a ressalva de que só podem fazê-lo, quando tais "conteúdos extras" são verificados pela direção e coordenação e aprovados para a utilização nas respectivas turmas de cada professor. As respostas também deixam claro que, se há a utilização de outros materiais, isso se dá a fim de que se ocupem as "brechas", "lacunas" e "fissuras" que o material não contempla.

Tal afirmação se justifica, pois fica pressuposto que o professor se mantenha "em dia" com a programação, façanha que, de acordo com alguns docentes, se conquista arduamente ao longo dos anos, ao se trabalhar com o material apostilado pré-elaborado, nas escolas municipais que adotam os cadernos didáticos apostilados, onde esses profissionais da educação, ou seja, professores trabalham.

\section{Compreensão daș lịmitações e possibilidades da prática pedagógica eścolar}

Quanto ao tempo de trabalho, as respostas variam de três a quinze anos de atividade docente entre a rede municipal pública e a rede particular de ensino, sendo que em ambas se adotam materiais apostilados. Apenas o Docente “ $D$ ”, revela lecionar na rede pública desde 2012, o que se dá, possivelmente, por ser recém-formado.

Dou aulas na rede pública municipal de ensino desde fevereiro de 2012 (Docente D).

No entanto, o comentário do “Docente D” evidencia que, apesar de ter concluído uma pós-graduação em uma universidade pública, a formação que possui na graduação vem de uma faculdade particular, assim como no caso dos outros sete professores. 
Tenho formação em Letras com habilitação em Português e Inglês. Minha graduação foi em Universidade Particular e tenho pós-graduação (especialização), pela UNESP em Araraquara-SP (Docente D).

Ministro aulas na rede pública de ensino há oito anos. Tenho licenciatura em Letras pela Puccamp (Docente G).

Dou aulas na rede pública de ensino há oito anos. Sou formado em Letras - Faculdade Particular (Docente C).

Leciono na rede pública de ensino há quaro anos. Graduei-me, primeiramente em Letras, com habilitação plena em Português/Inglês e, posteriormente, em Pedagogia. Ambas graduações foram realizadas em Instituições de ensino articular (Docente F).

Atuo na rede pública de ensino há cinco anos. Cursei Letras em Instituição Particular (Docente E).

Leciono faz sete anos, apenas em escolas públicas municipais. Minha graduação foi concluída em Instituição particular (Docente F).

Trabalho na rede pública de ensino há oito anos. Cursei Letras pela PUC - Instituição Particular (Docente H).

Em detrimento deste panorama educacional, das limitações e tensões a que os docentes estão sujeitos ao trabalhar nas escolas públicas municipais que optaram por adotar os materiais didáticos apostilados, é relevante apontar que os professores avaliados percebem sua atividade pedagógica, ou seja, se reconhecem como docentes. Isso pode ser notado nas respostas às perguntas 10, 11 e 12:

Imagino ser possível compreender minha atividade pedagógica a partir do momento que eu tenha criatividade e paciência. 0 material apostilado adotado pela secretaria municipal de ensino possui, sim, suas qualidades e posso explorar isso. Minhas sugestão é que os alunos pudessem trabalhar em dupla e não apenas individualmente, como propõem o material apostilado. Que as aulas pudessem ser remanejadas em dois momentos distintos: explicação com orientação do professor e atividade dos alunos. E algo ainda mais importante: que o material fosse mais atualizado e houvesse menos aulas para que nós, professores, trouxéssemos novas abordagens para complementar os cadernos apostilados, descentralizando os conteúdos fechados e mecanizados de tais apostilados (Docente A).

Quando o professor tem condição de ir além do conteúdo apostilado e seu saber e conhecer está acima daquele conteúdo pré-estabelecido, acredito que seja possível que sua atividade, enquanto docente, se dê aí. 0 professor é muito mais importe e muito melhor que qualquer apostilado. É material humano, é quem executa os conteúdos e faz o material engrenar, ou seja, seja funcionar de fato. Eu, particularmente, noto que a maior exigência em relação aos didáticos apostilados seja, sim, a obrigatoriedade de cumprir os conteúdos do caderno no tempo estabelecido pela escola. Em relação ao material apostilado utilizado eu sugeriria ao seguimento educacional, ou seja, a empresa franqueada que o elabora, que oportunizasse ao educador autonomia para executar aqueles conteúdos pré-elaborados aula a aula. E que compusessem conteúdos, cujo tempo de execução fosse determinado sem que nos pressionasse para concluí-lo exatamente no tempo que eles determinam (Docente B). 
Sim, além da absurda quantidade de atividades, percebo que as aulas pré-estabelecidas dos cadernos apostilados têm um conteúdo mecanizado, já que as informações, somente primam a memorização e a reprodução dos conceitos a serem ministrados. Eu penso que seja possível compreender minha atividade docente a partir do material, uma vez que mesmo sufocada por ele, ainda há a relação de ensino-aprendizagem, entre mim e meus alunos. 0 que mais tenciona, ou seja, atrapalham minhas práticas em sala se aula, é a falta e oportunidade e possibilidade, quase sempre, de trabalhar com meu alunos outras atividades. Sugeriria o uso textos do universo reflexivos e filosóficos, gêneros textuais que o material não utiliza. Tenho certeza de que isso possibilitaria aulas não só menos mecânicas, como também contribuiria a fim de que nosso aluno pensasse criticamente e, desse forma, suas dúvidas seriam respondidas de maneira pontual e esclarecedora (Docente C).

Minhas relação pedagógicas com os alunos tem se tornado cada vez mais "refinadas" e penso que trabalhar com o material apostilado na rede pública de ensino, ainda que em condições de muita pressão, é o que tem ajudado nesse exercício professoral. Em minha opinião, o pequeno espaço de tempo que a programação impõem, ainda seja o fator limitante de meu trabalho como docente, pois noto que meus alunos não retém o conteúdo, todos juntos, em uma mesma sintonia. Proporia à rede que elaborassem aulas extra apostila, sobretudo aquelas que os cadernos não contemplam, ou melhor ainda, que eu pudesse levar tais conteúdos sem cobrança ou fiscalização do direção e coordenação e que, além disso, houvesse um tempo maior a fim de que as aulas pudessem ser ministradas sem atropelo (Docente D).

Minhas relações pedagógicas seguem amadurecendo à medida que uma programação "pré-estabelecida" possibilita alguns espaços de criação na sala de aula, ainda que breves, autoritários e punitivos. Penso que é neste "jogo" tenso das relações nos espações institucionais e na sala de aula que me percebo como docente. Outro detalhe lamentável é, sem sombras de dúvidas o tempo reduzido para dar conta de todo conteúdo cobrado no cadernos apostilados. Eu se pudesse opinar e ser atendida sugeriria à franquia educacional que cria e repassa tais materiais aos municípios a elaboração de conteúdos que possibilitassem uma aprendizagem não mecânica e, sobretudo, que houvesse interação. Um grande começo seria ouvir os professores (Docente E).

Sim, pois ainda que percebo no material apostilado, um conjunto de imposições, pedagogicamente limitantes, e pré-estabelecidas, noto que todas essas tensões exercitam minha atividade prática docente à medida que vou aprendendo a lidar com o material que tenho em mãos. Porém, aquilo que mais me chateia é a pressão que tenho de passar, devido ao pouco tempo, para cumprir os cadernos apostilados. Me pergunto: Será que alguma vez seria ouvido em relação a isso? (Docente F).

Sim, creio ser possível compreender minha atividade docente usando o material apostilado, pois ainda que os conteúdos sejam "engessados", considero boa parte dos exercícios pelo menos adequados ao aprendizado. Para mim o cumprimento da programação é uma preocupação que me persegue o tempo todo, porém, depois de certo tempo de tanto sermos pressionados e cobrados, nos encaixamos ao ritmo. Meu lema é: "sempre que possível substituir e complementar os conteúdos a partir de material extra-apostila". Isso é claro, se direção e a coordenaação aprovar antes (Docente G).

O fato é que todo professor é um pesquisador do saber, indiferentemente dos espaços onde transitar. Isso pode ser a distância, presencial, apostilado, TV, rádio etc. 0 professor com excelente formação, achará, esteja onde estiver, uma maneira eficaz de alcançar seu aluno. Penso que todo indivíduo é capaz de se relacionar e aprender, sempre interagindo. 0 professor, nos espaços onde transitar, quer seja na pior rede de franquia escolar, tem capacidade, sim, de adaptar-se ao ambiente, ao tempo e ao espaço. Para isso é necessário que, primeiramente, deseje ser assertivo e seguir aos princípios e por que não as regras, muitas vezes já pré-estabelecidas e impostas. Minha sugestão às empresas educacionais que elaboram, divulga e distribuem materiais didáticos apostilados às escolas nas redes públicas e particulares: primeiro, que desvinculassem uma parte da avaliação das atividades e conteúdos da apostila e transpusessem outra parte a projetos diversificados. Isso permitiria uma eficaz flexibilização à maneira de ensinar e aprender e, além do mais, facultaria, isto é, facilitaria ao professo desenvolver metodologias particulares e revestidas de sentido (Docente $\mathrm{H}$ ). 

ensino e a utilização do material padronizado apostilado

Em relação ao questionamento sobre as possíveis propostas à empresa do segmento educacional - que elabora, distribui e divulga o pacote de materiais didáticos apostilados às secretarias de educação de ensino nos municípios - que poderiam tornar viável a atividade pedagógica em sala de aula, nota-se que algumas respostas, como a do Docente "G" e do Docente "F", seguem ligadas à importância de se ter uma direção que os ouvissem.

\begin{abstract}
Se pudesse opinar, sugeriria à direção e à coordenação, e antes de tudo à secretaria de educação, que compra os didáticos-apostilados, que os conteúdos pudessem ser flexibilizados, já que isso é condição mínima e necessárias ao aprimoramento da aprendizagem. Além do mais, que as necessidades dos alunos fossem atendidas, e, sobretudo as dos docentes, já que ele é o condutor capacitado dos conteúdos ministrados em sala de aula. E é claro, contar como uma direção mais flexível, que pudesse nos dar ouvidos (Docente $G$ ).
\end{abstract}

Bom seria se houvesse um coordenador pedagógico competente na unidade, com quem eu pudesse expor as minhas tensões de ter que trabalhar com esse material. Penso que nos entenderia e isso possibilitaria a criação de um canal de apoio, em especial em relação ao uso de outros materiais além-apostila sem burocracia, vigilância, controle e punição. E ainda: termos literal exercício de autonomia a fim de escolhermos quais aulas queremos ou não selecionar do material apostilado (Docente F).

\title{
Considerações finais
}

Na interação cotidiana, a relação material didático e profissional docente se figura enquanto relações de poder formal e impessoal, próprio das organizações burocráticas, regida em nome dos órgãos administrativos do sistema.

Tal poder funciona como um escudo e justificativa para o exercício do poder simbólico pelos dirigentes da instituição: os atores (professores) se submetem às ordens e exigências de superiores que as impõem enquanto "representantes" dos órgãos oficiais, os verdadeiros impositores.

Associar o poder simbólico ao poder formal e impessoal das organizações burocráticas pode parecer, à primeira vista, uma tarefa impossível. No entanto, foi esta a realidade observada nas escolas analisadas, nas relações do dia a dia: os atores (professores) interagem sob o comando de um material curricular apostilado "pré-programado", cujos apontamentos se figuram num poder simbólico reconhecido por todos e vivenciado sem muitos questionamentos.

Existem hierarquias a serem respeitadas, tarefas a serem executadas, regras a serem cumpridas e todo um aparato burocrático, definido em estatutos e regimentos pré-estabelecidos, que norteiam as ações e interações dos professores dentro da instituição. Desde o momento em que entram na escola até a hora da saída, são submetidos a uma série de regras para o exercício de suas atividades, às quais acatam em sinal de conivência com a ordem estabelecida.

Nessa relação hierárquica é exercido o poder impessoal, balizado nas normas regimentais, nas leis e nas ordens vindas dos órgãos administrativos do sistema de ensino. A ordem procede de cima e todos 
os atores envolvidos estão no mesmo barco, sujeitos ao mesmo estatuto e aos mesmos órgãos administrativos (matriz), independente das unidades (escolas) em que mantenham vínculo empregatício.

Dessa forma, o professor se encontra submetido ao poder e à vontade do material apostilado pré-estabelecido, uma vez que tal material trata-se da materialização da franquia. O material, por sua vez, representa um sistema de ensino que possui uma carga de poder, tanto própria escola e seu nome e dos autores do material, quanto das teorias científicas que as sustentam e as legitimam.

Nesse sentido, é importante ressaltar o argumento básico elaborado por Norbert Elias (1994a) de que há diferentes fontes de poder ${ }^{6}$ - a política, econômico, de conhecimento, dentre outras - e que estas se expressam de variadas formas. O poder é resultado das relações e, portanto, não é um fato posto e situado que pode ser isolado como algo qualquer, mas é relacional e faz parte das interações humanas. Segundo Elias,

o poder tem a ver com o fato que existem grupos ou indivíduos que podem reter ou monopolizar aquilo que os outros necessitam, como por exemplo, comida, amor, segurança, conhecimento, etc. Portanto, quanto maior as necessidades desses últimos, maior é a proporção de poder que detêm os primeiros (ELIAS, 1994b, p. 53).

É importante considerar que ao se referir ao poder em suas mais variáveis fontes (político, econômico, do conhecimento, e outros), Elias (1994b) também se refere a ele a partir de suas variadas formas. Isso se dá porque o monopólio dos diferentes núcleos de poder é que permite ao Estado se manter com um elevado potencial de poder.

Entretanto, considera Elias (1994b) que o monopólio desses fatores depende do monopólio do conhecimento como elemento que marca a emergência de um grupo de classes subalternas por meio das lutas pelo direito à educação, por exemplo. Todavia, o sentido do processo de monopolização que entende o poder de decisão como presente apenas nas mãos de um número cada vez menor de indivíduos, perde a ideia de um processo em relação com a longa duração. Para Elias (1986), não significa dizer que um número cada vez menor de pessoas se torna livre e, mais e mais pessoas se tornam não livres. Mas sim que,

se o movimento é considerado como um todo, podemos reconhecer sem dificuldades que - pelo menos em sociedade altamente diferenciadas - em certo estágio do processo a dependência passa por uma mudança qualitativa peculiar. Quanto mais pessoas são tomadas dependentes pelo mecanismo monopolista, maior se torna o poder dependentes, não apenas individual, mas também coletivamente, em relação a um ou mais monopólios (ELIAS, 1986, p. 100).

Assim, podemos destacar que a interdependência entre as classes sociais e os indivíduos dá margem a uma maior divisão de funções e à criação de instituições mais sólidas e, cedo ou tarde, força o poder monopolista à relação de dependência funcional diante de grupos com menor elemento de poder.

\footnotetext{
${ }^{6}$ As referências sobre o poder que abordo neste capítulo acerca dos conceitos de Norbert Elias são frutos de entrevista por ele concedida a Peter Lucas e publicada com o título "Conocimiento y Poder" e à obra "Os Estabelecidos e os Outsiders", escrito em parceria com J. Scotson.
} 
Será que poderíamos pensar que a busca deste equilíbrio de poder, para Elias, se configura como motor propulsor de todas as relações humanas? Em Introdução à Sociologia (1986, p. 87-112) isso aparece justamente quando trata dos"modelos de jogos" para pensar as relações sociais. Assim, afirma Elias que,

O equilíbrio do poder não se encontra unicamente na grande arena das relações entre os Estados, onde é frequentemente espetacular, atraindo grande atenção. Constitui um elemento integral de todas as relações humanas (ELIAS, 1986, p. 80).

Sendo assim, o poder é, de acordo com Elias (1986), fruto da interdependência, um atributo das relações. A proporção da função que uma pessoa desempenha em relação a outra, ou um grupo em relação a outro, é a base em que se constrói o "equilíbrio de poder". Foi esse sentido de um poder interrelacional que permitiu a Elias observar como variam as relações que se estabelecem entre uns grupos e outros, entre uns indivíduos e outros. Também tornou possível entender como variam as influências mútuas entre os grupos sociais em cada momento histórico e em amplos períodos (ELIAS, 1994a, p. 30).

Foi também esse aspecto que o permitiu entender o papel inter-relacional do Rei e sua corte na análise que fez da sociedade francesa em A Sociedade de Corte (ELIAS, 2001), bem como o papel do simples indivíduo na teia reticular dos indivíduos em A Sociedade dos Indivíduos (ELIAS, 1994b).

Por fim, como aponta Elias, o poder também se gesta na forma do conhecimento. Um novo tipo de conhecimento é também um novo local de poder. O poder potencial das massas está diretamente relacionado com o acesso a níveis mais elevados de educação. Como diria Elias, o "acesso a um conhecimento mais amplo, a maiores e mais compreensivos meios de orientação, incrementa o poder potencial dos grupos humanos" (ELIAS, 1994b, p. 57).

Portanto, muitas das características narradas até aqui ajudam a delimitar qual o real papel desempenhado pelos professores no interior deste quadro, cujo grande astro e centro da dinâmica empresarial, com suas unidades franqueadas ou parceiras municipais, trata-se do material sistematizado apostilado.

\section{Apêndice}

\section{Roteiro do questionário aplicado aos professores de língua portuguesa da rede pública municipal de ensino fundamental II}

1. Há quanto tempo você atua no magistério na rede pública de ensino?

2. Qual sua formação? Em Instituição pública ou particular?

3. Quantas aulas você ministra por semana? 

ensino e a utilização do material padronizado apostilado

4. Como você se sente em relação ao trabalho com o material apostilado sistematizado na escola pública municipal? Justifique a resposta.

5. Aponte quais são para você as maiores qualidades e os maiores defeitos deste material didático apostilado.

6. Existe a possibilidade de incorporação nas aulas de algum tipo de material extra apostila? Quais? De que forma você os utiliza?

7. Você cumpre a programação estabelecida pelas apostilas em tempo hábil? Justifique.

8. Você considera exigente a programação estabelecida pelo conteúdo apostilado? Por quê?

9. Como professor, você observa se há exigências produzidas pelo material apostilado didático que tenciona o saber e o conhecer de sua prática pedagógica? Justifique.

10. Você acha possível entender sua atividade docente a partir das relações pedagógicas, mediadas pelo material apostilado adotado na rede pública municipal de ensino? Justifique.

11. Qual(s) outra(s) exigência(s), em sua opinião, adotada(s) pela padronização de ensino apostilado, tenciona o conhecer e o saber da atividade docente no tempo e no espaço da sala de aula? Justifique.

12. No tocante ao material apostilado utilizado, qual (s) sugestão(s) você proporia ao sistema de ensino, que elabora o material apostilado e o repassa à escola pública municipal onde você atua, para tornar ainda mais viável em sala de aula sua atividade pedagógica? Justifique.

\section{Referências}

BATISTA, A. A. G. Um objeto variável e instável: textos, impressos e livros didáticos. In: ABREU, M. (Org.). Leitura, história e história da leitura. Campinas: Mercado de Letra, 2000.

BOURDIEU, P. A economia das trocas simbólicas. 5a Ed. São Paulo: Perspectiva, 1999.

BOURDIEU. Questões de Sociologia. Rio de Janeiro: Marco Zero, 1989.

BOURDIEU. Sur le pouvoir symbolique. Annales: Economies, sociétés, civilisations, v. 32, n. 3, 1977, p. 405-411.

ELIAS, N. A Sociedade de Corte. Rio de Janeiro: Jorge Zahar, 2001.

ELIAS. A Sociedade dos Indivíduos. Rio de Janeiro: Jorge Zahar, 1994b.

ELIAS. Conocimiento y Poder. Madrid: La Piquita, 1994a.

ELIAS. Introdução à Sociologia. Lisboa: Edições 70, 1986.

FOUCAULT, M. Microfísica do poder. 19. ed. São Paulo: Graal, 2004.

FOUCAULT. Vigiar e Punir. 22 Ed. Petrópolis: Vozes, 2000. 
A relação entre as práticas dos docentes na rede pública municipal de ensino e a utilização do material padronizado apostilado

GERALDI, J. W. Livro didático de língua portuguesa: a favor ou contra? Entrevista a Ezequiel Theodoro. Leitura, teoria e prática, v. 6, n. 9, 1987, p. 3-7.

LANDINI, T. S. Jogos habituais - sobre a noção de habitus em Pierre Bourdieu e Norbert Elias. In: SIMPÓSIO INTERNACIONAL PROCESSO CIVILIZADOR, 10. Anais... Campinas, 2007. Disponível em: https://bit. ly/2WDSQFo. Acesso em 23 dez. 2020.

MORAES, M. C. M. Recuo da teoria: dilemas na pesquisa em educação. Revista Portuguesa de Educação, v. 14, n. 1, 2001, p. 7-25. 